\title{
Том \\ Post-normal science communication: exploring the blurring boundaries of science and journalism
}

\section{Michael Brüggemann, Ines Lörcher and Stefanie Walter}

\begin{abstract}
This article provides a framework for analysing changes and continuities in science communication. The field is challenged by three contexts: (1) 'post-normal situations' of coping with uncertainties, value questions, an urgency to take action, and associated political pressures; (2) a dramatically changing media environment, and (3) a polarizing discourse culture. We refine the concept of post-normal science to make it more applicable to analyse public science communication in an era of digital media networks. Focussing on changes in the interactions between scientists and journalists, we identify two ideal types: normal and post-normal science communication, and conclude that the boundaries of science and journalism are blurring and under renegotiation. Scientists and journalists develop new shared role models, norms, and practices. Both groups are increasingly acting as advocates for common goods that emphasize the emerging norms of post-normal science communication: transparency, interpretation, advocacy and participation.
\end{abstract}

Keywords

DOI

Introduction
Environmental communication; Science and media; Science communication: theory and models

https://doi.org/10.22323/2.19030202

Submitted: 20th April 2019

Accepted: 11th May 2020

Published: 1st June 2020

Since 2017, the "Marches for Science" have drawn many scientists out of their offices and labs and onto the streets. In 2019, youths mobilized for climate protection in weekly "Climate Strikes" and "Fridays for Future" marches. Within a few weeks, over 26,800 supporters and scientists, (mostly) from Germany, Austria, and Switzerland signed the "Scientists for Future" declaration supporting these protests [scientists4future, 2019]. During the 2020 Coronavirus crisis, extensive daily podcasts featuring virologists reached broad mass audiences. These are examples of "scientist citizens", [Pietrucci and Ceccarelli, 2019] who diverge from the ideal-typical and traditional role of the "pure scientist", who pursues research disconnected from society and the world of values, interests and political conflicts [Pielke, 2007]. 
These examples of fast-paced mobilizations of scientists were enabled by the recent revolution of the technological media environment: digital networks facilitate information sharing, coordination and mobilizing at unprecedented speeds, and now circumvent journalists as the traditional gatekeepers of public communication [Couldry and Hepp, 2016]. The fact that scientific issues (and science as an institution) have been dragged into polarizing political conflicts has also mobilized scientists [Sunstein, 2017; Bennett and Pfetsch, 2018; Post, 2019; McCarty, 2019]. In this article, we provide a framework for analysing the changes (and continuities) in science communication with a focus on the changing norms and practices of journalists and scientists.

We argue that media and wider socio-cultural transformations lead to challenges, renegotiations and changes not only for the role of scientists in the public communication process, but also the entire figuration [Hepp, Breiter and Hasebrink, 2018] of actors, norms and communicative practices involved in science communication. While these changes do not necessarily replace the traditional order of science communication, given the relative stability of social structures and culture, they are likely to complement existing science communication practices. In addition, new norms and role interpretations are likely to be challenged. The increasing complexity and contradictions constitute a formidable challenge for the study of science communication.

We suggest that applying Funtowicz and Ravetz's [1993] concept of post-normal science (PNS) to the field of communication helps in analysing these emerging changes. PNS is based on the idea that science is challenged by post-normal situations that are defined by four features: (1) Science produces high levels of uncertainty and a considerable degree of ignorance due to a lack of data, the complexity of the subject matter, or a focus on projections of future risks. (2) Developing science-based policy advice in this context involves value questions that cannot be answered through scientific inquiry. (3) The issues at hand are very relevant to society, and involve high costs or benefits. (4) Political decision-making is urgent [Funtowicz and Ravetz, 1993]. PNS as a framework helps to understand how science reacts to these situations.

The concept of PNS is useful, as post-normal situations have become the new normal in some scientific fields, including climate change research, genetic engineering, prenatal diagnostics, artificial intelligence, and the mining of big data. It is not only the frequent occurrence of post-normal situations, however, but also their combination with recent changes in the media and the political landscape that drives the emergence of PNS communication. We acknowledge that roles and norms are likely to change only slowly, but argue that due to the emergence of digital networks and the increasing polarization of political discourse [Sunstein, 2017; Bennett and Pfetsch, 2018], PNS communication is much more likely to evolve today than in the 1990s, when the concept of PNS was originally developed.

We assume that the emergence of PNS, combined with (a) a drastically changing media environment and (b) a polarized society, has led to a blurring between and a renegotiation of the professional boundaries of the stakeholders involved in science communication. Based on this assumption, we developed the concept of PNS communication as presented in this article in order to provide a framework for describing and explaining changes in science communication. 


\section{Analytical framework for researching changes in science communication}

We define PNS communication as communication among relevant actors in the field of science communication who react to post-normal situations. These post-normal situations, combined with the changing media environment and a polarized society, shape and challenge the professional roles and norms that underlie their communication practices.

We define norms according to Giddens [2001] as rules of behaviour that reflect or embody a culture's values. Norms may be linked to roles when types of behaviour expected from an individual occupying a particular social position are concerned [Giddens, 2001]. Norms and roles may include rules about how to communicate in public, and they are negotiated in communicative practices.

Science communication can be understood broadly as "how society talks about science" [Bucchi and Trench, 2014, p. 10]. This type of communication deals with "scientific issues" as well as "public issues involving science" [Wynne, 2014, p. 64], and should be studied as the "co-evolution of science, society and communication media" [Bucchi and Trench, 2014, p. 9]. While there are multiple channels through which science communication can take place, e.g., museums, science centres, documentaries, or popular science books [Burns, O'Connor and Stocklmayer, 2003; Longnecker, 2016], in the following we will limit ourselves to the closer analysis of the changing norms and communicative practices of two professions: journalists and scientists. Their communicative activities and interactions today go beyond interviews published in traditional mass media, but also include new media channels such as blogs, social media, or online video-sharing platforms.

The rise of professional science public relations and the rise of digital media have engaged a multitude of voices in science communication beyond journalists and scientists. Since an exhaustive exploration of the field - which extends to diverse actors ranging from educational institutions to civil society, politics and the lay public - is beyond the scope of this article, we focus on scientists and journalists as two professional groups whose interactions remain to be one of the central elements of science communication.

Figure 1 visualises our analytical framework: the emergence of post-normal situations of science, media change and polarization are important drivers of the shift towards post-normal patterns of science communication. We suggest focusing research on analysing the changing norms, roles, and meta-discourses that help orient and legitimize communicative practices of scientists and journalists.

Specific norms are a distinctive feature of science communication. Science communication differs from other forms of public communication, such as political communication, as it happens under the influence of (or in conflict with) the norms of science [Jamieson, 2017]. Jamieson asserts that science communication should follow general science norms. She warns that the dynamics of communication have repercussions for the field of science itself: "When the norms of science are violated by science communicators, science itself is called into question" [Jamieson, 2017, p. 18].

New norms and roles do not remain uncontested. Their renegotiation can be observed empirically in meta-discourses in which actors legitimate their practices and renegotiate and reflect communicative roles and norms. Carlson [2016] has argued that in the field of journalism, "metajournalistic discourses", which are 
described "as public expressions evaluating news texts, the practices that produce them, or the conditions of their reception" (p. 350), define and legitimate journalism and (re)draw its boundaries. The concept may also apply to other institutions such as science. Intensified meta-discourses are themselves an indicator of change, because they show that existing roles, norms and practices are no longer taken for granted.

Finally, practices may not always reflect the prevalent roles and norms. Thus, it is fruitful to compare roles and role enactment empirically. Previous studies in the journalism literature have done so, albeit without a focus on science communication [see, e.g., Mellado and van Dalen, 2013].

In the following, we first discuss 'normal' patterns of interactions between scientists, journalists and their audiences, their guiding norms and practices, and then describe 'post-normal' science communication of scientists and journalists. Finally, we discuss the implications of the observed changes for society, which feed back into the trend of social polarization (as indicated in Figure 1).

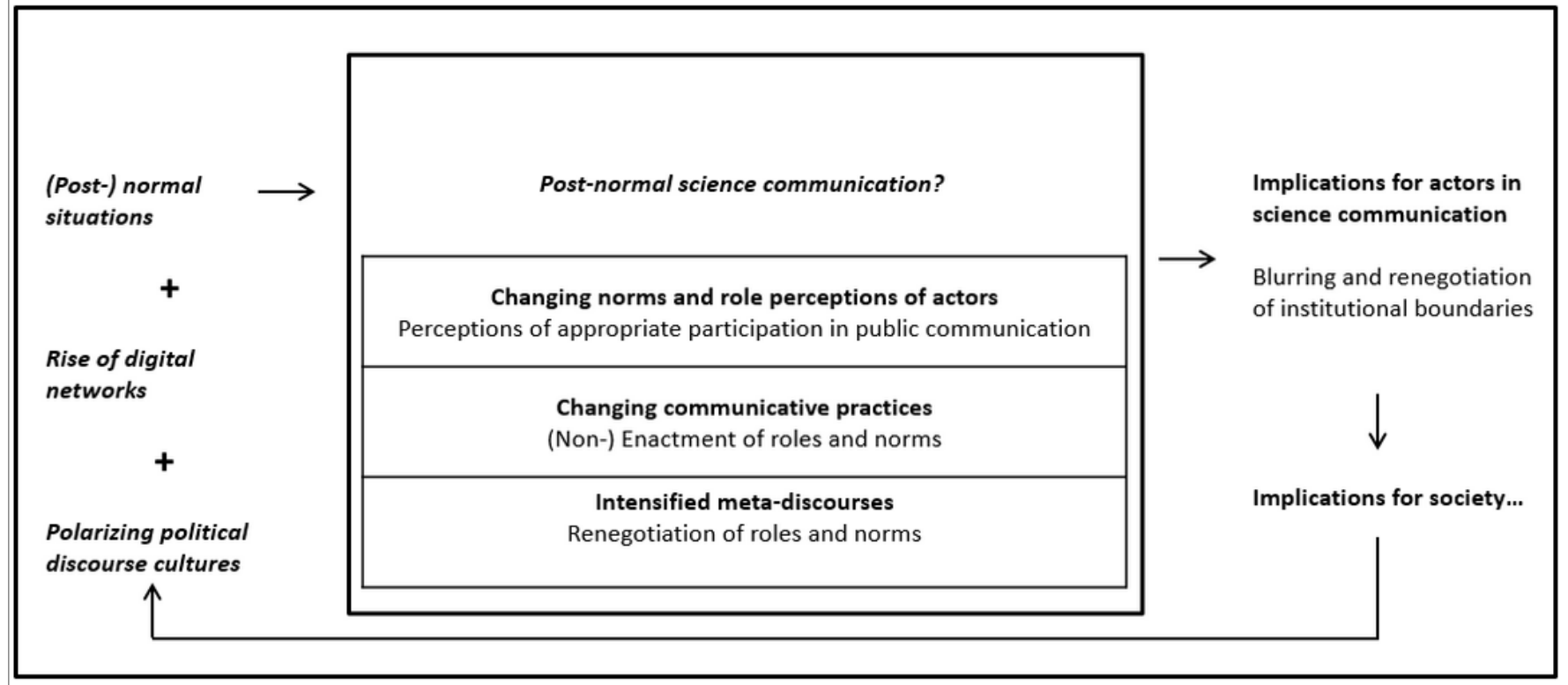

Figure 1. Analytical framework for exploring post-normal science communication.

We consider both normal and PNS communication to be ideal types of science communication. The PNS framework does not suggest that there ever was a state of pure 'normal science' that has magically transformed into a post-normal phase [see also Turnpenny, Jones and Lorenzoni, 2010, p. 301]. Science communication will always consist of a mixture of both models [Brüggemann, 2017]. Nor do scholars who embrace post-normal science (as a normative concept) advocate replacing traditional scientific practices with post-normal practices. Rather, they recommend post-normal practices as a complement to normal science in the specific case of post-normal situations [Kønig, Børsen and Emmeche, 2017]. 
'Normal' science communication by journalists and scientists
The "normal modus" of science is "puzzle solving" within a given paradigm that generates a slowly growing body of consistent knowledge [Kuhn, 1970, p. 35ff]. Another metaphor capturing this view is the "boy scout model of science" [Turnpenny, 2012]: scientists simply have to discover scientific knowledge.

Normal science also entails a specific idea about the science-policy interface: scientists deliver facts to politicians, including occasional warnings about problems they discover. These facts translate into policy advice. Science communication involves the transfer of scientific knowledge (and recommendations based on that knowledge) to decision-makers and the larger public. This linear model of science communication involves scientists who produce findings that journalists then translate for the wider (and mostly passive) public.

Normal science does not assume that scientists take a pro-active role in communicating with stakeholders and the public [Dunwoody and Ryan, 1985; Schneider, 1986; Goodell, 1977]. Scientists who "turn to the public" — and thus transgress the boundaries of the profession - have traditionally been perceived as exhibiting deviant behaviour, which ought to only occur in "marginal situations" [Bucchi, 1996, p. 375]. "Pure scientists" primarily focus on their research and are not concerned about its possible applications; as such, they have no direct connection with policy-makers or politics in general [Pielke, 2007]. Yet, some scientists are passively involved in science communication and provide responses to policy-makers upon request (the "science arbiter" in Pielke's typology).

Surveys and qualitative studies demonstrate that when interacting with journalists, scientists are expected to respond to questions related to their own research and refrain from making broader comments [Rödder, 2012]. The commonly accepted role of scientists also entails not actively approaching the media and not communicating their research findings prior to peer review. Scientists clearly discriminate between two arenas: an open debate within the scientific community and a more limited discussion of scientific results in the wider public arena [Peters, 2013]. Interactions between journalists and scientists are depicted as generally harmonious.

One explanation for this harmonious relationship could be that both institutions share the same basic epistemology: facts and truth should be confirmed via empirical observation. Journalism "has borrowed its epistemological perspective and ideals from modern science" [Eide and Kunelius, 2012, p. 16], namely the norms related to the concept of objectivity [Deuze, 2005; Schudson, 2001]. Journalism has "claimed the mantle of scientific realism to ground its approach to truth-telling - focusing facts, utilizing quasi-scientific methods, and bracketing ideology and subjectivity" [Waisbord, 2018, pp. 4-5]. This marriage of science and journalism in producing facts and truth is part of a wider public agreement that science is the exclusive provider of knowledge [Waisbord, 2018]. Science journalists often communicate scientific findings as detached observers - a role which entails finding an interesting angle to sell the news story and refraining from critically investigating the scientific process of knowledge production [Stocking, 1999; Dunwoody, 2014].

The background consensus on how (normal) science communication should be conducted is based on an acknowledgement of the autonomy of science and 
journalism - from both each other and from political and/or economic advocacy [Jung, 2012; Deuze, 2005; Hujanen, 2016]. According to this consensus, scientists are expected to avoid becoming advocates, including "stealth advocates" [Pielke, 2007], meaning that scientists seem to focus on science, but in reality follow a political agenda. Likewise, the role of a neutral disseminator receives the most support among journalists around the world; however, they also perceive themselves as having several other roles depending on the political, cultural and newsroom context [Weaver and Willnat, 2012; Hanitzsch, Hanusch and Ramaprasad, 2019].

The traditional notion of professional autonomy among scientists and journalists also involves denying access to outsiders. A central aspect of communication within scientists' inner arena is that amateurs should not be allowed to access scientific data, or to participate in decision-making about research questions, methods or the peer review process. The same is true for the journalistic newsroom, which has traditionally been shielded from audience participation.

Occasional misunderstandings and frictions between journalists and scientists occur due to the lack of transparency about each other's working methods. For example, both may strive for objectivity, but in different ways [Post, 2015]. In science, objectivity is interpreted as following the scientific method to ensure the validity, reliability and intersubjectivity of research [Popper, 2008]. Objectivity in journalism, however, traditionally refers to the provision of true, accurate, (socially) relevant and impartial information through balanced, fair and neutral coverage [Westerstahl, 1983]. As Gans [1979] describes in his classic newsroom ethnography, US journalists historically refrained from joining a party or other political activities - and even from talking about politics to their colleagues - in order to remain professionally detached and objective [for a more elaborated discussion of the concept, see Schudson, 2001]. Yet objectivity, although a widely shared aspiration in journalism, has always been contested [Galison, 2015].

Merton [1942] summarized the ethos of (normal) science as a set of four norms: communism, universalism, disinterestedness, and organized scepticism (CUDOS). Communism (in this context) means serving the scientific community by making scientific results available; today, we would call it communalism. Universalism refers to the pursuit of knowledge that is valid across social and cultural contexts. Disinterestedness requires scientists to pursue their research impartially, and not to serve any special interests. Organized scepticism is the norm behind mechanisms such as the peer review process. While Merton's norms have been criticised [see e.g. Ziman, 2002], they still serve as a reference point for thinking about ethics in science and science communication [Medvecky and Leach, 2017].

Yet, current scientific practices diverge from these norms, as Bray and von Storch [2017] have shown for climate scientists. While this might represent the usual difference between norms and practice, such divergences may also indicate changes in the norms guiding (climate) scientists.

Organized scepticism as a scientific norm [Merton, 1942] - enacted in practices related to the peer review process - and the idea of serving the scientific community are specific to the domain of science, while journalists tend to emphasize their service to their audience and the wider public [Deuze, 2005] (see Table 1). The task of writing news stories that engage broad audiences 
is exclusive to journalists, who do so by ensuring that their coverage captures public attention [Eilders, 2006]. Immediacy — the fast reporting of newsworthy and relevant material - is another value that sets journalists and scientists apart. These differences explain why the academic literature in the 1980s and early 1990s maintained that journalists and scientists had two different professional cultures [Peters, 1995] and described them as "strangers to each other, not able to understand each other's language, and driven by different agendas" [Peters, 2013, p. 14102].

Table 1. Changes in the science communication by scientists and journalists.

\begin{tabular}{|c|c|c|}
\hline & Scientists & Journalists \\
\hline \multicolumn{3}{|c|}{ Ideal-typical 'normal' science communication } \\
\hline Roles & $\begin{array}{l}\text { Pure scientist } \\
\text { Science arbiter [Pielke, 2007] }\end{array}$ & $\begin{array}{l}\text { Neutral observer } \\
\text { Watchdog [Weaver and Willnat, 2012; Hanitzsch, } \\
\text { 2011; Hanitzsch, 2013] }\end{array}$ \\
\hline \multirow[t]{4}{*}{ Norms } & \multicolumn{2}{|c|}{ Autonomy [Jung, 2012; Hujanen, 2016] } \\
\hline & $\begin{array}{l}\text { Objectivity (scientific): scientific method: } \\
\text { validity, reliability, intersubjectivity, falsification } \\
\text { [Popper, 2008] } \\
\text { Organized scepticism [Merton, 1942] }\end{array}$ & $\begin{array}{l}\text { Objectivity (journalistic): } \\
\text { (true/accurate, relevant), balanced/fair } \\
\text { coverage [Westerstahl, 1983] }\end{array}$ \\
\hline & Service to scientific community [Merton, 1942] & $\begin{array}{l}\text { Public service [Deuze, 2005]: information on } \\
\text { relevant current events, critic/control; serving } \\
\text { audiences }\end{array}$ \\
\hline & & Immediacy [Deuze, 2005] \\
\hline \multirow[t]{3}{*}{ Practices } & \multicolumn{2}{|c|}{$\begin{array}{l}\text { Limiting access to outsiders (to raw data, journalistic sources, decision-making about } \\
\text { research/editorial agenda, methods etc.) }\end{array}$} \\
\hline & Peer review & $\begin{array}{l}\text { Separation of reporting and commentary } \\
\text { Selection and emphasis on news factors [Eilders, } \\
\text { 2006] }\end{array}$ \\
\hline & $\begin{array}{l}\text { Restricted/passive communication with the pub- } \\
\text { lic: responding to requests from politics (for ad- } \\
\text { vice) or journalism (for information), restricted to } \\
\text { own research results, after peer review [Peters, } \\
\text { 2014; Rödder, 2012] }\end{array}$ & $\begin{array}{l}\text { Coexistence of active and passive practices in } \\
\text { communication with the public (indexing of elite } \\
\text { sources but also investigative reporting) }\end{array}$ \\
\hline \multicolumn{3}{|c|}{ Emerging common patterns of 'post-normal' science communication } \\
\hline Roles & \multicolumn{2}{|c|}{$\begin{array}{l}\text { Advocates of common goods (ecology, democracy, scientific/press freedom) } \\
\text { Brokers (of consensus, dialogue, ideas, knowledge) }\end{array}$} \\
\hline Norms & \multicolumn{2}{|c|}{$\begin{array}{l}\text { Advocacy [Wilke and Morton, 2015; Pielke, 2007] } \\
\text { Interpretation beyond facts/research results, e.g., weight of evidence reporting [Brüggemann and } \\
\text { Engesser, 2017; Dunwoody, 2005] } \\
\text { Limited transparency: methods / production process, own values, uncertainties [Hellmueller, Vos } \\
\text { and Poepsel, 2013; Karlsson, 2010] } \\
\text { Limited participation [Allan and Ewart, 2015; Funtowicz and Ravetz, 1993; Hujanen, 2016] } \\
\text { Public service formerly primarily a journalistic norm is increasingly also relevant for research } \\
\text { Immediacy formerly primarily a journalistic norm, might also become relevant for researchers as } \\
\text { they try to feed their knowledge into public discussions and political decision-making }\end{array}$} \\
\hline Practices & \multicolumn{2}{|c|}{$\begin{array}{l}\text { Pro-Active communication with the public: scientists and journalists interact intensively with act- } \\
\text { ors from other professional spheres (talking about research results before peer review, publishing on } \\
\text { blogs, connecting on Twitter); provide context/interpretation beyond facts; stating one's values }\end{array}$} \\
\hline
\end{tabular}

Table 1 summarizes this ideal-typical description of the normal roles, norms, and practices of scientists and journalists around a common normative core consisting of claims to autonomy and objectivity. 
The changing

media and socio-political context of science communication
This rough and ideal-typical description of a well-ordered universe of the relationship of science and journalism has been upended by a number of different forces that challenge the traditional boundaries of professional journalism, science and other social institutions. Science communication is changing in the context of broader and interrelated trends towards the development of what analysts have called a world risk society [Beck, 2001], knowledge society [Stehr, 1994] and network society [Castells, 1996]. The growing importance of assessments of the global risks faced by human society (as posited in the concept of risk society), and the increasing relevance of knowledge for the economy and politics (as implied in the term 'knowledge society'), have enhanced the importance of science for society.

One important driver of change in science communication is the rising significance of mediated communication. Mediatization is understood as (1) the increasing influence of media logics in other social domains [Mazzoleni and Schulz, 1999]. Journalists' decision-making criteria (such as news factors) might influence the way in which scientists communicate their findings to the public. Mediatization also describes (2) the increasing pervasiveness of media technologies, which has turned modern ways of living into media cultures or "cultures of mediatization" [Hepp and Tribe, 2013]. The emergence of digital networks (including the web and social media, but also the use of email or instant messaging) enhances connectivity [Couldry and Hepp, 2016] by enabling actors from formerly separated institutional spheres to connect and interact in new ways. By creating multiple new networks, connectivity has challenged the power of the traditional institutional gatekeepers of communication: journalists and media outlets are no longer needed as intermediaries to reach audiences; political and civil society actors or scientists who want to communicate directly with stakeholders and the public can easily circumvent the media [e.g. Walter and Brüggemann, 2020]. Within organizations (e.g., newsrooms and universities), public relations professionals can no longer control the message. Therefore, social media networks can have a "destabilizing" effect on institutional structures, as they allow "unauthorized commentary" from influential individuals [Couldry, 2012, p. 41]. The close connection between different types of actors in social networks might furthermore encourage the norms of professional practice from one field to spill over to another, thus blurring and redefining the borders of formerly separated domains such as journalism, science, and political advocacy. Many scientists, and most journalists, now use social media in their professional lives [Hedman and Djerf-Pierre, 2013; Van Noorden, 2014; Walter, Lörcher and Brüggemann, 2019]. Below we discuss how this might affect the roles, norms and practices of scientists and journalists involved in science communication.

The second driver of changes in science communication is the broader trend of the polarization of public discourses mirroring a society that is increasingly divided along ideological lines [for the extreme case of the United States, see Sunstein, 2017]. The increasingly partisan traditional media and the polarizing echo chamber effects of social media foster these processes of polarization, leading to "disrupted public spheres" [Bennett and Pfetsch, 2018].

All of these trends hint at a much closer coupling of science and its social contexts, which raises concerns about a loss of scientific autonomy [Weingart, 2002]. Science has become politicized and mediatized and scientists are drawn into political conflicts as experts who serve political purposes [Weingart, 2002]. Their actions 
sometimes follow media logics rather than scientific logics [see a number of contributions in several edited volumes on science communication such as Rödder, Franzen and Weingart, 2012; Bucchi and Trench, 2014]. Yet, due to a lack of broader empirical studies, the extent to which these changes constitute the mediatization of science - i.e., the redefinition of normal behaviour in science communication - is unclear [Schäfer, 2014]. It is possible for science as a "system" (with its own code and logic) to survive, but for changes to occur on the lower level of the "programs" of academic organizations [Weingart, 2012]. We suggest that the old "normal" programs are complemented, rather than replaced, by "post-normal" practices of science communication.

PNS as an analytical and normative concept
PNS, as outlined by Funtowicz and Ravetz [1993], starts from the assumption that future developments are unpredictable and uncontrollable. It takes a plurality of perspectives on "reality" as legitimate. Science is expected to actively manage the uncertainties associated with its findings, be transparent about the value questions involved, and engage with an extended peer community when formulating policy advice. Scientists from other disciplines, as well as journalists, civil society organizations, or even lay people could become part of this extended peer community that evaluates the policy conclusions that follow from scientific findings. Transparency, robustness, uncertainty management, sustainability and transdisciplinarity are the norms that are supposed to complement Merton's CUDOS in the PNS framework [Kønig, Børsen and Emmeche, 2017]. Robustness refers to methodological as well as social robustness: the inclusion of a broad range of relevant actors ensures that science-based policy advice will be acceptable to all stakeholders involved.

Many misunderstandings surrounding the concept of PNS derive from confusing these normative recommendations with a description of how scientists actually act in post-normal situations. While research on climate change has been identified as the prototype of PNS [Krauss, Schäfer and Storch, 2012], it also clearly diverges from the normative model outlined above, as the following description of the climate debate in the early $21^{\text {st }}$ century shows: "little room was left for discussing inherent uncertainties or the normative assumptions that underlie the science-public interaction. Instead, the tendency to silence sceptical voices increased. The public climate debate turned into an almost confessional war with its own dynamics between 'us' and 'them,' alarmists and sceptics, believers and deniers. [...] the IPCC tried to normalize the post-normal situation by emphasizing scientific authority" [Krauss, Schäfer and Storch, 2012, p. 122, 127]. According to this description, the post-normal situation of climate change affected science communication, but not in a way that is in line with the demands attached to PNS as a normative model.

To examine the actual changes that have taken place, we suggest defining PNS as scientific roles, norms and practices that emerge from post-normal situations and diverge from established norms of science. This involves using an inductive approach to identify changes in norms and practices under the conditions of PNS rather than merely checking whether scientists follow the normative framework of PNS.

For example, observing that some scientists working on a post-normal issue, such as climate change, tend to leave aside rather than explain uncertainties in research 
[Post, 2016], diverges from Funtowicz and Ravetz's recommendations to openly address uncertainties. Yet such practices, following our suggestion, would still be labelled "PNS communication", if they diverge from traditional practices and can plausibly be linked to the specific characteristics of post-normal situations.

Therefore, when analysing a given phenomenon in science communication, the first step would be to clarify whether it can be linked to the features of a post-normal situation (high uncertainties, values involved, high stakes, urgent decision-making). A second analytical step should identify the reactions of actors to this situation. A third step then compares what is actually happening to PNS as a normative framework of participatory and transparent science. In a final step, one may try to explain why the actual outcomes of post-normal situations diverge under certain instances from the normative framework: are there situations in which leaving aside uncertainties forms part of scientists' professional communication practices, such as, when giving a 15-second statement on TV?

Past research has neither sufficiently theorized nor comprehensively researched the implications of PNS for public science communication. This may be because the debate surrounding PNS has largely gone unnoticed by media and journalism scholars, despite its important implications for science communication in journalistic media and other types of public arenas.

If scientists comply with the recommendations of PNS as a normative framework, they would have to engage in a dialogue with society and publicly accept other (non-scientific) views as legitimate. They would have to engage with the public throughout the research process - not only after the publication of their research. Furthermore, they would have to discuss both the uncertainties and the value questions associated with their research, and when moving from scientific research results to policy advice. Participating in debates about the limits of scientific certainty and one's own values is likely to lead to debates about the authority, public role and some of the core values of science. The image of the pure scientist as a disinterested, value-free researcher, who freely shares his or her knowledge but does not engage in advocacy, cannot be upheld in the world of PNS communication.

Emerging norms of journalists and scientists in post-normal science communication
Table 1 provides a first rough picture of the communicative roles, norms and practices of scientists and journalists that are emerging in the current situation of PNS communication, which is characterized by (a) the proliferation of science in post-normal situations, (b) media change and (c) polarizing societies. We argue that the evidence from previous studies suggests an increasing salience of a number of common norms in science communication that are shared by journalists and scientists. This convergence of norms is due to the common pressures for change. We formulate the following preliminary propositions to inspire future empirical research that tests them thoroughly.

Proposition 1: the rise of advocacy. We argue that scientists and journalists are drawn into the world of advocacy because politicians and lobbyists use scientific knowledge for political causes, and scientists (at least in the case of climate science) and journalists themselves are coming under attack, particularly when interacting 
with the new wave of populists that political polarization has brought to power. The urgency of decision-making as a feature of post-normal situations, such as the current climate crisis, tends to draw actors from the side-lines into the field of politics. The result may be that scientists and journalists become advocates, but not necessarily in the conventional and narrow sense of pursuing self-interest or partisan politics. The example of the Marches for Science illustrates that some scientists have become advocates of broader goods and values such as the freedom and professional authority of science. Journalists are likely to develop a similar type of advocacy for their field.

Beyond this anecdotal evidence regarding the mobilization of scientists for causes such as climate protection or freedom of science, there is empirical evidence that both journalists and scientists use digital media to express opinions in addition to presenting facts or research results. Studies have shown that scientists use Twitter extensively to share their opinions [Walter, De Silva-Schmidt and Brüggemann, 2017]. Also, journalists have used blogs [Singer, 2005] and Twitter [Lasorsa, Lewis and Holton, 2012] to communicate factual reporting and to offer comments and opinions. Yet, other studies demonstrate that advocacy as a norm remains contested in both the scientific [Wilke and Morton, 2015] and journalistic communities [Fahy and Nisbet, 2011; Hiles and Hinnant, 2014]. The proponents of constructive journalism, a notion that could be viewed as a prototype of post-normal journalism [Brüggemann, 2017], do not promote advocacy. They claim that journalism should not only cover certain problems and their background, but also possible solutions to these problems [Dyer, 2015]. They remain within the limits of the dominant Anglo-Saxon journalistic self-conception of the detached observer [Aitamurto and Varma, 2018].

Future research should investigate more closely what type of advocacy scientists and journalists support or reject. PNS advocates do not pursue a narrow self- or party interest. Scientists might not personally gain from defending the institution of science; they might even suffer personal disadvantages by being drawn into political conflicts with, for example, actors who deny anthropogenic climate change. For individual scientists, it might be much more self-serving to remain 'pure' and avoid becoming a target of public anger. We therefore expect the co-existence of old and new role perceptions, with the role model of scientists and journalists as advocates of common goods becoming more salient.

Proposition 2: journalists and scientists as brokers of dialogue. Another emerging role that differs from both advocacy and the non-communicating pure scientist is the broker. Roger Pielke [2007] originally named this role the "honest" broker, but this label may be understood to imply that other role conceptions are dishonest. The communicative role of the broker is post-normal as it responds to the need to broker between conflicting ideas and values at the intersection of science and politics. Jürgen Habermas' notion of the public sphere similarly contains the normative concept of journalists as brokers of democratic discourse [Brosda, 2008]. There is also empirical evidence that science journalists sometimes go beyond their traditional conduit or watchdog role and act as "curators" or "conveners" [Fahy and Nisbet, 2011] — which may be subsumed under the role of the broker. 
Proposition 3: journalists and scientists are interpreters of facts and scientific findings. Interpretation is an emerging norm of PNS communication that serves the discursive role of the broker of dialogue. With many actors involved in science communication, and conflicting claims about what is considered fact and scientific truth, journalists and scientists cannot simply provide factual information about events or scientific findings. They must also put these facts into context, if they do not want to leave this up to bloggers or readers in the comments section. Recent studies have provided initial evidence to back up these claims, particularly with regards to the post-normal issue of climate change: balanced reporting on climate science is increasingly frequently replaced by "weight-of-evidence reporting" that provides the context to help readers determine which claims are backed by the general state of research, and which represent fringe positions [Dunwoody, 2005; Brüggemann and Engesser, 2017; Hiles and Hinnant, 2014; Fahy and Nisbet, 2011].

In order to provide the appropriate interpretations and contexts, science journalists also have to become more involved in science. They need to be able to distinguish scientific evidence from unwarranted claims of scientific expertise, for example from self-made online experts on issues such as climate change or vaccination. Consequently, post-normal journalism is expected to become knowledge journalism, which is augmented by in-depth knowledge about science, including its processes and methods of knowledge production. Journalism is thus expected to go 'upstream' in the flow of knowledge, and report not only on the results of studies, but also on how science is conducted [Nisbet and Fahy, 2015]. A study of climate journalism shows that journalists covering the topic fall into either the small group of high-expertise "prolific writers", or the large group of "occasional climate journalists", who more or less follow the lead of the few journalists who understand the science of climate change [Brüggemann and Engesser, 2014].

To some extent, this means recovering the scientific expertise that was lost as science journalists were laid off in the last two decades in the course of the newspaper financing crisis [Dunwoody, 2014]. What appears to be new, compared to traditional science journalism, is the emphasis on going "up-stream" in reporting, not primarily related to research findings but also with regards to the social contexts of research in action, including: why do we ask certain research questions and neglect others?

Proposition 4: participation and transparency within limits. The norm of participation implies that there is an extended peer community, as advocated by [Funtowicz and Ravetz, 1993]. Expanding the peer community - and thus the value of participation - was a normative demand in the 1990s. Today, it has become an inevitable condition of digital public spheres: new actors have emerged as visible voices in science communication, regardless of whether or not they were invited to participate. Lay people participate in scientific discourse, for example via user comments on news websites [Lörcher and Taddicken, 2017].

Networks of blogs denying climate change are a case in point. Ravetz argues that the debates regarding the publication of climate scientists' personal e-mails (coined "Climategate") were an "exemplification of post-normal science, with the role of extended peer community being filled by the critics on the blogosphere" [2011, p. 149]. Facing criticism from all sides, Ravetz also explained that the idea of an "extended peer community" was not an "invitation to mob rule in science". It was 
not meant to become a "replacement peer community" [2011, p. 156]. Our point is that participation, as well as advocacy, has become part of science communication in some areas, generating PNS communication, for better or worse.

Participation, as the anecdote above shows, can be ambivalent and tensions remain about drawing the line between citizen scientist and scientist (citizen journalist and journalist, respectively) [Allan and Ewart, 2015; Hujanen, 2016]. Journalists consider the participation of non-experts to be only somewhat helpful [Örnebring, 2013]. Yet, public participation is welcomed in some contexts, such as investigative journalism and crowdsourcing [Hujanen, 2016]. A tension between participation and professional control remains [Lewis, 2012]: journalists' unwillingness to link to non-journalists (e.g., in Tweets or in their news articles) demonstrates that the traditional gatekeepers defend their professional territory [Lasorsa, Lewis and Holton, 2012]. The involvement of citizen scientists has become the new normal in some areas of science [see e.g. Dickinson et al., 2012]. Yet, there is the phenomenon of boundary work, where both scientists [Gieryn, 1999] and journalists [Carlson, 2015] engage in defending their professions against perceived intrusions from outsiders.

Transparency is another norm that is widely advocated but not fully enacted in professional practice. The basic change in professional norms of communication is well-captured in the title of a blog post: "transparency is the new objectivity" [Weinberger, 2009]. In journalism studies (but less so in journalism), demands for greater transparency abound [Karlsson, 2010; Singer, 2007]: the gathering, organization and dissemination of information should be open and accountable for everybody [Kovach and Rosenstiel, 2014] — within and outside the newsroom [Deuze, 2005]. Scientists and many academic journals also demand more transparency in science, including access to data sets, methodological decisions, and scripts for analysis that should be made publicly available [Nature Geoscience, 2014]. Transparency, therefore, clearly is a norm that has been emerging for some decades in the sense of encouraging greater openness about the process of knowledge and news production. It also entails the disclosure of remaining uncertainties, as advocated by Funtowicz and Ravetz [1993].

Yet, the norm of transparency is also contested, even in journalism [Vos and Craft, 2017], and demands for greater transparency are not necessarily enacted in journalistic practice [Karlsson, 2010].

Setting limits to both participation and transparency makes perfect sense from the point of view of protecting the sanctum of the profession against intruders. In post-normal situations of increasing conflicts and attacks on the profession, it may well be advisable to become more transparent and enable participation. Yet an alternative scenario that is no less plausible is excluding the public as much as possible. This approach would include not talking about uncertainties in science, which is exactly the opposite of the recommendations by Funtowicz and Ravetz [1993].

Proposition 5: spill-over of the norms of immediacy and public service orientation from journalism to science. Mediatization theory asserts that some norms are likely to spill over from the journalistic to the scientific sphere and change the "programs" of the system [Mazzoleni and Schulz, 1999; Weingart, 2012]. 
We expect more of this in PNS communication. For instance, immediacy is a norm in journalism, but less so in science. Both as an adaptation to media logics (as posited in the mediatization hypothesis) and as a result of striving for research results that are relevant to currently debated problems, scientists might more frequently orient their science communication towards the norm of immediacy (e.g., expressed by intensified pro-active communication of scientists via podcasts during the Corona-crisis).

Scientists increasingly communicate with the public and have more media contacts [Peters, 2013], but in a survey of German climate scientists only about $18 \%$ claimed that they consider media interest when making decisions about research questions or publishing strategies [Ivanova et al., 2013]. The core of scientific autonomy remains intact despite a blurring of the boundaries. The latter might also entail spill-overs in the other direction (not included in the mediatization hypothesis): scientific concepts of objectivity (i.e., using scientific methods) might spill over to specialized science or data journalists.

Finally, both professions might increasingly emphasize their public service orientation, which in the case of science also diverges from the traditional orientation towards the scientific community. Evidence of this can be found in self-descriptions of science organizations and in funding agencies' demands to deliver socially useful knowledge [National Science Foundation, 2019].

The mostly passive and restrictive communication practices of scientists and many journalists are becoming more pro-active [Peters, 2013; Walter, Lörcher and Brüggemann, 2019]. These practices are also beginning to involve more frequent interactions with actors from other professional spheres and the erosion of some historical restrictions of science communication, such as talking about research results only after peer review and publication.

Conclusion and future research
We have argued that the concept of PNS is useful for analysing changes in science communication, particularly given the growing importance of digital media networks and the polarization of public discourses. We have defined PNS communication as occurring in post-normal situations and departing from traditional patterns of science communication. Focusing on scientists and journalists - two important professional groups concerned with science communication - we have examined findings from prior studies to be more concrete about which norms and roles are likely to change, and how.

The emerging patterns of post-normal science communication of journalists and scientists seem to be based on the norms of transparency, interpretation, advocacy and participation. Past research has sometimes failed to look closer at what these norms actually mean in today's debates among scientists and journalists. For example, advocacy is not necessarily about partisanship or promoting some kind of self-interest, but advocacy of common goods such as freedom of speech or sustainability. Thus, there is a lot of room for future research into the patterns of post-normal science communication.

Future empirical work should test and refine our framework, and determine whether advocacy, interpretation, public service and immediacy are really on the 
rise across the institutional boundaries of science and journalism. Future studies should also explore this for other actor groups involved in science communication. While this article was neither able to consider the entirety of actors nor communication channels relevant to science communication, we believe that our conceptual framework can be applied to the wider field of science communication affected by post-normal conditions. It remains up to future studies to test whether this is actually the case: how do e.g. science public relations professionals react in post-normal situations in today's world of digital media and polarized discourses? How have the norms and practices of curators of exhibitions in science centres changed in post-normal situations? We do not expect that all of the changes diagnosed for scientists and journalists also apply for all other professions involved in science communication, but we assume that roughly the same drivers of change will also have modified their practices towards their own version of post-normal science communication.

The way forward should entail the following five steps:

first, meta-discourses about professional roles should be assessed more closely and broadly. Such discourses can be found, e.g., in science blogs or social media, or in discussions with audiences at public science events. Such analyses can determine whether meta-discourses are indeed on the rise, and which roles and values are advocated or rejected.

Second, the practices of science communication should be explored using longitudinal data that can track changes across time, for example by performing content analysis on journalistic articles, social media outlets or blogs. An alternative would be to repeat landmark studies of science communication. This is fairly easy with quantitative surveys, but it would also be worthwhile to try to replicate qualitative studies.

The third step for future research would be comparative work testing whether our assumptions about post-normal patterns of science communication are more prominent in certain communication channels, media outlets and social contexts than others. At the societal level, the effects of different degrees of polarization on post-normal patterns can be examined, for instance, by comparing climate debates in countries where the anthropogenic nature of climate change is more or less contested. We expect that in certain media contexts (social media) and in more polarized societies, PNS has a greater influence on changing patterns of science communication.

The fourth step is to assess the implications of post-normal patterns of science communication for both the institutions of science and journalism and for society as a whole. Does being transparent about value questions and uncertainty enhance or damage these institutions' credibility and reputation? Does advocating public goods prevent or lead to the further polarization of society?

Finally, we should discuss and debate normative questions: what is our stance on the post-normal values of participation, transparency, advocacy and public service? And more importantly, what kind of participation, transparency and advocacy is desirable? All three trends may help to advance society, but they may also increase the polarization of discourses. There are reasons why participation has thus far 
only taken place within certain limits. Advocacy — understood as seeking benefits for oneself or a specific group or organization - is likely to foster polarization, but advocating common goods may create common ground across party lines. Both transparency and participation may also be organized in ways that are likely to be more or less beneficial to democracy. Thus, more research on this is needed, as is more self-reflection on the norms that we share as researchers and science communicators.

Acknowledgments

The ideas presented in this article have been inspired by and refined in discussions with colleagues on different occasions over the last five years. Particularly, we would like to thank: Risto Kunelius, Hartmut Wessler, Uwe Hasebrink, Lance Bennett, Hans von Storch, Birte Fähnrich, Simone Rödder, Max Boykoff, Irene Neverla, the three anonymous reviewers of this article and, last but not least, Nancy Longnecker, who as the editor, has done an outstanding job in providing guidance during the review process.

\section{References}

Aitamurto, T. and Varma, A. (2018). 'The constructive role of journalism'. Journalism Practice 12 (6), pp. 695-713. https://doi.org/10.1080/17512786.2018.1473041.

Allan, S. and Ewart, J. (2015). 'Citizen science, citizen journalism: New forms of environmental reporting'. In: The Routledge Handbook of Environment and Communication. Ed. by A. Hansen and R. Cox. Abingdon, London and New York: Routledge, pp. 186-196.

Beck, U. (2001). World risk society. Cambridge, U.K.: Polity.

Bennett, W. L. and Pfetsch, B. (2018). 'Rethinking political communication in a time of disrupted public spheres'. Journal of Communication 68 (2), pp. 243-253. https://doi.org/10.1093/joc/jqx017.

Bray, D. and von Storch, H. (2017). 'The normative orientations of climate scientists'. Science and Engineering Ethics 23 (5), pp. 1351-1367. https://doi.org/10.1007/s11948-014-9605-1.

Brosda, C. (2008). Diskursiver Journalismus — Journalistisches Handeln zwischen kommunikativer Vernunft und mediensystemischem Zwang. Wiesbaden, Germany: VS Verlag für Sozialwissenschaften. https://doi .org/10.1007/978-3-531-90769-7.

Brüggemann, M. and Engesser, S. (2014). 'Between Consensus and Denial: Climate Journalists as Interpretive Community'. Science Communication 36 (4), pp. 399-427. https://doi.org/10.1177/1075547014533662.

Brüggemann, M. (2017). 'Post-normal journalism: climate journalism and its changing contribution to an unsustainable debate'. In: What is sustainable journalism? Integrating the environmental, social and economic challenges of journalism. Ed. by P. Berglez, U. Olausson and M. Ots. New York, NY, U.S.A.: Peter Lang U.S., pp. 57-73. https: //doi .org/10.3726/b11462.

Brüggemann, M. and Engesser, S. (2017). 'Beyond false balance: how interpretive journalism shapes media coverage of climate change'. Global Environmental Change 42, pp. 58-67. https: //doi .org/10.1016/j.gloenvcha.2016.11.004.

Bucchi, M. (1996). 'When scientists turn to the public: alternative routes in science communication'. Public Understanding of Science 5 (4), pp. 375-394. https://doi.org/10.1088/0963-6625/5/4/005. 
Bucchi, M. and Trench, B., eds. (2014). Routledge Handbook of Public Communication of Science and Technology. 2nd ed. London, U.K. and New York, U.S.A.: Routledge. https://doi .org/10.4324/9780203483794.

Burns, T. W., O'Connor, D. J. and Stocklmayer, S. M. (2003). 'Science Communication: A Contemporary Definition'. Public Understanding of Science 12 (2), pp. 183-202. https://doi.org/10.1177/09636625030122004.

Carlson, M. (2015). 'Introduction. The many boundaries of journalism'. In: Boundaries of journalism. Professionalism, practices and participation. Ed. by M. Carlson and S. C. Lewis. London, U.K.: Routledge, pp. 1-18. https://doi.org/10.4324/9781315727684.

- (2016). 'Metajournalistic discourse and the meanings of journalism: definitional control, boundary work and legitimation'. Communication Theory 26 (4), pp. 349-368. https://doi.org/10.1111/comt. 12088.

Castells, M. (1996). The information age. Economy, society and culture. Volume 1: the rise of the network society. Cambridge, MA, U.S.A.: Blackwell.

Couldry, N. (2012). Media, society, world. Social theory and digital media practice. Cambridge, U.K. and Malden, MA, U.S.A.: Polity.

Couldry, N. and Hepp, A. (2016). The mediated construction of reality. New York, NY, U.S.A.: Wiley.

Deuze, M. (2005). 'What is journalism? Professional identity and ideology of journalists reconsidered'. Journalism: Theory, Practice \& Criticism 6 (4), pp. 442-464. https: //doi.org/10.1177/1464884905056815.

Dickinson, J. L., Shirk, J., Bonter, D., Bonney, R., Crain, R. L., Martin, J., Phillips, T. and Purcell, K. (2012). 'The current state of citizen science as a tool for ecological research and public engagement'. Frontiers in Ecology and the Environment 10 (6), pp. 291-297. https://doi.org/10.1890/110236.

Dunwoody, S. (2005). 'Weight-of-evidence reporting: what is it? why use it?' Nieman Reports 59 (4), pp. 89-90. URL: http://www.nieman.harvard.edu/reports/arti cle/100595/Weight-of-Evidence-Reporting-What-Is-It-Why-Use-It . aspx.

- (2014). 'Science journalism: prospects in the digital age'. In: Routledge Handbook of Public Communication of Science and Technology. Ed. by M. Bucchi and B. Trench. 2nd ed. London, U.K. and New York, U.S.A.: Routledge, pp. 27-39. https://doi .org/10.4324/9780203483794.

Dunwoody, S. and Ryan, M. (1985). 'Scientific barriers to the popularization of science in the mass media'. Journal of Communication 35 (1), pp. 26-42. https://doi.org/10.1111/j.1460-2466.1985.tb01882.x.

Dyer, J. (2015). 'Solutions journalism'. Nieman Reports 69 (2), pp. 14-17. URL: http: //niemanreports.org/articles/is-solutions-journalism-the-solution/.

Eide, E. and Kunelius, R. (2012). 'Introduction'. In: Media meets climate. The global challenge for journalism. Ed. by E. Eide and R. Kunelius. Göteborg, Sweden: Nordicom, pp. 9-30.

Eilders, C. (2006). 'News factors and news decisions. Theoretical and methodological advances in Germany'. Communications 31 (1). https://doi.org/10.1515/commun.2006.002.

Fahy, D. and Nisbet, M. C. (2011). 'The science journalist online: Shifting roles and emerging practices'. Journalism 12 (7), pp. 778-793. https://doi.org/10.1177/1464884911412697.

Funtowicz, S. O. and Ravetz, J. R. (1993). 'Science for the post-normal age'. Futures 25 (7), pp. 739-755. https ://doi .org/10.1016/0016-3287 (93) 90022-L. 
Galison, P. (2015). 'The journalist, the scientist and objectivity'. In: Objectivity in science. New perspectives from science and technology studies. Boston Studies in the Philosophy and History of Science 310. Ed. by F. Padovani, A. Richardson and J. Tsou. Cham, Switzerland: Springer International Publishing, pp. 57-78. https://doi.org/10.1007/978-3-319-14349-1_4.

Gans, H. J. (1979). Deciding what's news. A study of CBS Evening News, NBC Nightly News, Newsweek and Time. 1st ed. New York, NY, U.S.A.: Pantheon Books.

Giddens, A. (2001). Sociology. 4th ed. Vol. Polity Press. Cambridge, U.K.: Polity Press.

Gieryn, T. F. (1999). Cultural Boundaries of Science: Credibility on the Line. Chicago, U.S.A.: University of Chicago Press. URL: https : / /www. press . uchica go.edu/ucp/books/book/chicago/C/bo3642202.html.

Goodell, R. (1977). The visible scientists. Boston, U.S.A.: Little, Brown and Co.

Hanitzsch, T. (2011). 'Populist disseminators, detached watchdogs, critical change agents and opportunist facilitators'. International Communication Gazette 73 (6), pp. 477-494. https: //doi .org/10.1177/1748048511412279.

- (2013). 'Journalism, participative media and trust in a comparative context'. In: Rethinking journalism. Trust and participation in a transformed news landscape. Ed. by C. Peters and M. Broersma. New York, NY, U.S.A.: Routledge, pp. 200-209. https://doi.org/10.4324/9780203102688.

Hanitzsch, T., Hanusch, F. and Ramaprasad, J. (2019). Worlds of journalism. Journalistic cultures around the globe. New York, NY, U.S.A.: Reuters Institute global journalism series, Columbia University Press.

Hedman, U. and Djerf-Pierre, M. (2013). 'The social journalist. Embracing the social media life or creating a new digital divide?' Digital Journalism 1 (3), pp. 368-385. https://doi.org/10.1080/21670811.2013.776804.

Hellmueller, L., Vos, T. P. and Poepsel, M. A. (2013). 'Shifting journalistic capital?' Journalism Studies 14 (3), pp. 287-304. https://doi.org/10.1080/1461670x.2012.697686.

Hepp, A., Breiter, A. and Hasebrink, U., eds. (2018). Communicative figurations. Cham, Switzerland: Springer International Publishing. https://doi.org/10.1007/978-3-319-65584-0.

Hepp, A. and Tribe, K. (2013). Cultures of mediatization. Cambridge, U.K. and Malden, MA, U.S.A.: Polity.

Hiles, S. S. and Hinnant, A. (2014). 'Climate change in the newsroom: journalists' evolving standards of objectivity when covering global warming'. Science Communication 36 (4), pp. 428-453. https://doi.org/10.1177/1075547014534077.

Hujanen, J. (2016). 'Participation and the blurring values of journalism'. Journalism Studies 17 (7), pp. 871-880. https://doi .org/10.1080/1461670x.2016.1171164.

Ivanova, A., Schäfer, M. S., Schlichting, I. and Schmidt, A. (2013). 'Is there a medialization of climate science? Results from a survey of German climate scientists'. Science Communication 35 (5), pp. 626-653. https://doi.org/10.1177/1075547012475226.

Jamieson, K. H. (2017). 'The need for a science of science communication: communication science's values and norms'. In: The Oxford handbook of the science of science communication. Ed. by K. H. Jamieson, D. M. Kahan and D. A. Scheufele. Oxford, U.K.: Oxford University Press. https://doi.org/10.1093/oxfordhb/9780190497620.013.2. 
Jung, A. (2012). 'Medialization and credibility: paradoxical effect or (re)-stabilization of boundaries? Epidemiology and stem cell research in the press'. In: The sciences' media connection - public communication and its repercussions. Sociology of the Sciences Yearbook. Ed. by S. Rödder, M. Franzen and P. Weingart. Dordrecht, The Netherlands: Springer Netherlands, pp. 107-130. https://doi .org/10.1007/978-94-007-2085-5_6.

Karlsson, M. (2010). 'Rituals of transparency'. Journalism Studies 11 (4), pp. 535-545. https://doi.org/10.1080/14616701003638400.

Kønig, N., Børsen, T. and Emmeche, C. (2017). 'The ethos of post-normal science'. Futures 91, pp. 12-24. https://doi.org/10.1016/j.futures.2016.12.004.

Kovach, B. and Rosenstiel, T. (2014). The elements of journalism. What newspeople should know and the public should expect. 3rd ed. New York, NY, U.S.A.: Three Rivers Press.

Krauss, W., Schäfer, M. S. and Storch, H. von (2012). 'Post-normal climate science'. Nature and Culture 7 (2), pp. 121-132. https://doi.org/10.3167/nc.2012.070201.

Kuhn, T. S. (1970). The structure of scientific revolutions. 4th ed. Original publication year (1962). Chicago, IL, U.S.A.: University of Chicago Press. URL: https://books . google. com/books?id=3eP5Y_00uzwC\&pgis=1.

Lasorsa, D. L., Lewis, S. C. and Holton, A. E. (2012). 'Normalizing Twitter: journalism practice in an emerging space'. Journalism Studies 13 (1), pp. 19-36. https://doi.org/10.1080/1461670x.2011.571825.

Lewis, S. C. (2012). 'The tension between professional control and open participation'. Information, Communication \& Society 15 (6), pp. 836-866. https://doi.org/10.1080/1369118X.2012.674150.

Longnecker, N. (2016). 'An integrated model of science communication - More than providing evidence'. JCOM 15 (05), Y01. URL: https://jcom.sissa.it/archive/15/05/JC0M_1505_2016_Y01.

Lörcher, I. and Taddicken, M. (2017). 'Discussing climate change online. Topics and perceptions in online climate change communication in different online public arenas'. JCOM 16 (02), A03. https://doi .org/10.22323/2.16020203.

Mazzoleni, G. and Schulz, W. (1999). "“Mediatization" of politics: a challenge for democracy?' Political Communication 16 (3), pp. 247-261. https://doi.org/10.1080/105846099198613.

McCarty, N. M. (2019). Polarization. What everyone needs to know. New York, NY, U.S.A.: Oxford University Press.

Medvecky, F. and Leach, J. (2017). 'The ethics of science communication'. JCOM 16 (04), E. URL: https://jcom.sissa.it/archive/16/04/JCOM_1604_2017_E.

Mellado, C. and van Dalen, A. (2013). 'Between rhetoric and practice'. Journalism Studies 15 (6), pp. 859-878. https://doi.org/10.1080/1461670x.2013.838046.

Merton, R. K. (1942). The sociology of science. Theoretical and empirical investigations. Chicago, IL, U.S.A.: University of Chicago Press.

National Science Foundation (2019). Broadening participation. URL: https://www.nsf.gov/od/broadeningparticipation/bp.jsp.

Nature Geoscience (2014). 'Towards transparency'. Nature Geoscience 7 (11), pp. 777-777. https://doi.org/10.1038/ngeo2294.

Nisbet, M. C. and Fahy, D. (2015). 'The need for knowledge-based journalism in politicized science debates'. The Annals of the American Academy of Political and Social Science 658 (1), pp. 223-234.

https://doi.org/10.1177/0002716214559887. 
Örnebring, H. (2013). 'Anything you can do, I can do better? Professional journalists on citizen journalism in six European countries'. International Communication Gazette 75 (1), pp. 35-53. https://doi.org/10.1177/1748048512461761.

Peters, H. P. (1995). 'The interaction of journalists and scientific experts: co-operation and conflict between two professional cultures'. Media, Culture $\mathcal{E}$ Society 17, pp. 31-48.

- (2013). 'Gap between science and media revisited: Scientists as public communicators'. Proceedings of the National Academy of Sciences 110 (Supplement 3), pp. 14102-14109. https://doi.org/10.1073/pnas.1212745110. PMID: 23940312.

- (2014). 'Scientists as public experts. Expectations and responsibilities'. In: Routledge Handbook of Public Communication of Science and Technology. Ed. by M. Bucchi and B. Trench. 2nd ed. London, U.K. and New York, U.S.A.: Routledge, pp. 70-82. https://doi.org/10.4324/9780203483794.

Pielke, R. A. J. (2007). The Honest Broker. Cambridge, U.S.A.: Cambridge University Press.

Pietrucci, P. and Ceccarelli, L. (2019). 'Scientist citizens: rhetoric and responsibility in L'Aquila'. Rhetoric and Public Affairs 22 (1), pp. 95-128. https://doi.org/10.14321/rhetpublaffa.22.1.0095.

Popper, K. R. (2008). The logic of scientific discovery. London, U.K.: Routledge classics. Routledge.

Post, S. (2015). 'Scientific objectivity in journalism? How journalists and academics define objectivity, assess its attainability and rate its desirability'. Journalism: Theory, Practice \& Criticism 16 (6), pp. 730-749. https://doi.org/10.1177/1464884914541067.

- (2016). 'Communicating science in public controversies: strategic considerations of the German climate scientists'. Public Understanding of Science 25 (1), pp. 61-70. https://doi.org/10.1177/0963662514521542.

- (2019). 'Polarizing communication as media effects on antagonists. Understanding communication in conflicts in digital media societies'. Communication Theory 29 (2), pp. 213-235. https://doi.org/10.1093/ct/qty022.

Ravetz, J. R. (2011). "Climategate' and the maturing of post-normal science'. Futures 43 (2), pp. 149-157. https: //doi.org/10.1016/j. futures. 2010.10.003.

Rödder, S. (2012). 'The Ambivalence of Visible Scientists'. In: The Sciences' Media Connection - Public Communication and its Repercussions. Ed. by S. Rödder, M. Franzen and P. Weingart. Vol. 28. Sociology of the Sciences Yearbook. Dordrecht, The Netherlands: Springer, pp. 155-177. https://doi.org/10.1007/978-94-007-2085-5_8.

Rödder, S., Franzen, M. and Weingart, P., eds. (2012). The Sciences' Media Connection - Public Communication and its Repercussions. Vol. 28. Sociology of the Sciences Yearbook. Dordrecht, The Netherlands: Springer. https://doi.org/10.1007/978-94-007-2085-5.

Schäfer, M. S. (2014). 'The media in the labs, and the labs in the media: what we know about the mediatization of science'. In: Mediatization of communication. Ed. by K. Lundby. Berlin, Germany: De Gruyter Mounton, pp. 570-593.

Schneider, S. H. (1986). 'Both sides of the fence: the scientist as source and author'. In: Scientists and journalists: reporting science as news. Ed. by S. M. Friedman, S. Dunwoody and C. L. Rogers. New York, NY, U.S.A.: Free Press, pp. 215-222. 
Schudson, M. (2001). 'The objectivity norm in American journalism'. Journalism: Theory, Practice \& Criticism 2 (2), pp. 149-170. https://doi.org/10.1177/146488490100200201.

scientists4future (2019). Stellungnahme. URL: https://www. scientists4future .org/stellungnahme/.

Singer, J. B. (2005). 'The political j-blogger: 'normalizing' a new media form to fit old norms and practices'. Journalism: Theory, Practice \& Criticism 6 (2), pp. 173-198. https://doi.org/10.1177/1464884905051009.

- (2007). 'Contested autonomy. Professional and popular claims on journalistic norms'. Journalism Studies 8 (1), pp. 79-95. https://doi.org/10.1080/14616700601056866.

Stehr, N. (1994). Knowledge societies. London, U.K.: Sage.

Stocking, H. S. (1999). 'How journalists deal with scientific uncertainty'. In: Communicating uncertainty. Media coverage of new and controversial science. Ed. by S. M. Friedman, S. Dunwoody and C. S. Rogers. Mahwah, NJ, U.S.A.: Lawrence Erlbaum Associates, pp. 23-41.

Sunstein, C. R. (2017). \#Republic. Divided democracy in the age of social media. Princeton, NJ, U.S.A.: Princeton University Press.

Turnpenny, J. R. (2012). 'Lessons from post-normal science for climate science-sceptic debates'. Wiley Interdisciplinary Reviews: Climate Change 3 (5), pp. 397-407. https://doi.org/10.1002/wcc.184.

Turnpenny, J. R., Jones, M. and Lorenzoni, I. (2010). 'Where now for post-normal science? A critical review of its development, definitions and uses'. Science, Technology, \& Human Values 36 (3), pp. 287-306. https://doi.org/10.1177/0162243910385789.

Van Noorden, R. (2014). 'Online collaboration: Scientists and the social network'. Nature 512 (7513), pp. 126-129. https: //doi .org/10.1038/512126a.

Vos, T. P. and Craft, S. (2017). 'The discursive construction of journalistic transparency'. Journalism Studies 18 (12), pp. 1505-1522. https://doi.org/10.1080/1461670x.2015.1135754.

Waisbord, S. (2018). 'Truth is what happens to news'. Journalism Studies 19 (13), pp. 1866-1878. https://doi.org/10.1080/1461670x.2018.1492881.

Walter, S. and Brüggemann, M. (2020). 'Opportunity makes opinion leaders: analyzing the role of first-hand information in opinion leadership in social media networks'. Information, Communication \& Society 23 (2), pp. 267-287. https://doi.org/10.1080/1369118x.2018.1500622.

Walter, S., De Silva-Schmidt, F. and Brüggemann, M. (2017). 'From “knowledge brokers" to opinion makers: how physical presence affected scientists' Twitter use during the COP21 climate change conference'. International Journal of Communication 11, pp. 570-591.

URL: https://ijoc.org/index.php/ijoc/article/download/6016/2254.

Walter, S., Lörcher, I. and Brüggemann, M. (2019). 'Scientific networks on Twitter: analyzing scientists' interactions in the climate change debate'. Public Understanding of Science 28 (6), pp. 696-712. https://doi.org/10.1177/0963662519844131.

Weaver, D. H. and Willnat, L., eds. (2012). The global journalist in the $21^{\text {st }}$ century. New York, NY, U.S.A.: Routledge.

Weber, M. (1988). Gesammelte Aufsätze zur Wissenschaftslehre. Original publication year (1922). Tübingen, Germany: Mohr. 
Weinberger, D. (19th July 2009). 'Transparency is the new objectivity'. Joho the Blog. URL: http://www . hyperorg. com/blogger/2009/07/19/transparency-is-thenew-objectivity/.

Weingart, P. (2002). 'The moment of truth for science. The consequences of the 'knowledge society' for society and science'. EMBO reports 3 (8), pp. 703-706. https://doi.org/10.1093/embo-reports/kvf 165.

- (2012). 'The Lure of the Mass Media and its Repercussion on Science'. In: The Sciences' Media Connection - Public Communication and its Repercussions. Ed. by S. Rödder, M. Franzen and P. Weingart. Vol. 28. Sociology of the Sciences Yearbook. Dordrecht, The Netherlands: Springer, pp. 17-32. https://doi.org/10.1007/978-94-007-2085-5_2.

Westerstahl, J. (1983). 'Objective news reporting: general premises'. Communication Research 10 (3), pp. 403-424. https : //doi.org/10.1177/009365083010003007.

Wilke, A. K. and Morton, L. W. (2015). 'Climatologists' patterns of conveying climate science to the agricultural community'. Agriculture and Human Values 32 (1), pp. 99-110. https://doi.org/10.1007/s10460-014-9531-5.

Wynne, B. (2014). 'Further disorientation in the hall of mirrors'. Public Understanding of Science 23 (1), pp. 60-70. https://doi.org/10.1177/0963662513505397.

Ziman, J. (2002). Real Science: What it Is and What it Means. Cambridge, U.K.: Cambridge University Press.

\section{Authors}

Michael Brüggemann holds the Chair of Communication Research, Climate and Science Communication at the Institute for Journalism and Communication Research, Universität Hamburg. His work focuses on the study of journalism, political communication, and science communication from a comparative and transnational perspective (http:/ / bruegge.net/). E-mail: michael.brueggemann@uni-hamburg.de.

Ines Lörcher holds a Ph.D. in communication science and was senior researcher at the Chair of Communication Research, Climate and Science Communication at the Institute for Journalism and Communication Studies, Universität Hamburg. She works as counsellor and researches climate change, digital, as well as science communication. E-mail: ines.loercher@uni-hamburg.de.

Stefanie Walter holds a Ph.D. in political science and is senior researcher at the Center for Media, Communication and Information Research (ZeMKI) of the University of Bremen. Her research interests are in political and climate change communication, as well as in computational social science and text analysis. E-mail: Stefanie.Walter@uni-bremen.de.

\section{How to cite}

Brüggemann, M., Lörcher, I. and Walter, S. (2020). ‘Post-normal science communication: exploring the blurring boundaries of science and journalism'. JCOM 19 (03), A02. https:/ / doi.org/10.22323/2.19030202. 